\title{
Development strategy of informative footpaths of the Crimea
}

\author{
Svetlana Kalinkina ${ }^{1,{ }^{*}}$, Maria Nikiforova $^{1}$, Valentina Kulik $^{1}$, Natalya Lazitskaya $^{1}$ and Irina \\ Tregulova ${ }^{1}$
}

${ }^{1}$ Sevastopol Institute of Economics and Humanities (branch) of the Crimean Federal University named after V.I. Vernadsky", Sevastopol, Russia

\begin{abstract}
In modern conditions of development of the Russian tourism market, the practice of introducing "informative paths" routes as one of the forms of interpretation of a healthy lifestyle and a desire to protect the environment is becoming popular. For high-quality functioning of walking routes in Russia in general and the Republic of the Crimea in particular, it is necessary to carry out systematization and expert assessment of old routes, to carry out routine planning of the new ones. For the development and deployment of the existing and new informative walking tours, working out and adaptation of the development strategy of such tourist routes are necessary. The authors claim that a necessary element in developing a strategy for organizing informative walking tours is the diagnosis of the current strategy for managing informative walking tourism. During the research, its own development strategy of modern informative footpaths was developed, which is based on four main forms of strategic development: strategy of growth, development strategy, strategy of business, and strategy of competitiveness. Proceeding from the proposed mechanisms for the development strategy of informative footpaths, quality indicators can be achieved through a methodical approach to the development of a strategy for the development of "informative paths" to achieve compliance with the requirements of the tourist services market, existing goals, forms, methods, procedures, and projects.
\end{abstract}

\section{Introduction}

In works of domestic and foreign authors (Birzhakov M.B., Dolzhenko G.P., Zorin I.V., Kvartalnov V. A., Zakaldayev N.V. and others), all popular types of tourism are investigated, but the problem of informative walking tourism remains not fully explored. Recently, there has been a growing interest in popularizing active tourism in the world, since most people choose outdoor activities to maintain their health and gain new impressions. That is why there is a need to develop a strategy for the development of "footpaths".

\footnotetext{
*Corresponding author: sergiiblack@mail.ru
} 
The purpose of the paper is the research of the market of informative walking tourism and development of the strategy for the development of "informative paths" in the Crimea.

\section{Results}

Despite the fact that Thomas Cook is called the "father" of the modern world tourism industry (the first organized tour, 1841), in the history of tourism of the Crimea and the Russian Empire already at the beginning of the XIX century, there were numerical published "guides" (Sumarkov P.I., The travel across all the Crimea and Bessarabia in 1799 - M., 1800.; Izmaylov V.V. Travel to midday Russia. - M - 1805; Montadon Sh. The Crimea guide of the traveler. - Odessa, 1834), which had different recommendations for travelers, a set of routes and information on their duration. The presence of such factual material gives grounds to speak about the existence of organized and planned tourism in the Russian Empire and in particular in the Crimea at the end of the XVIII - the beginning of the XIX centuries.

The organizers of the first traveler clubs in Russia in the XIX century indicated one of the reasons for the need to popularize tourism - criminal indifference and lack of knowledge of their native land. Thus, in the charter of the Crimean Mountain Club, one of the pioneers of tourist activities in Russia, the following purposes of tourism were defined:

"1. Scientific research of the Taurian mountains and dissemination of the data collected about them;

2. Encouragement for visiting and exploring these mountains and facilitating the stay of natural scientists and artists traveling to the mountains for scientific or artistic purposes;

3. Support for local agricultural and small mining industries;

4. Protection of rare mountain plant species and animals" [2].

Researchers explain today's interest in tourism by other factors: increased interest in heritage, the availability of a sufficient amount of personal finances, increased free time, increased mobility, greater access to works of art and cultural heritage, and a high level of education. The positioning of tourism as an informative field of activity requires the presence of a full-fledged tourist product. Recreational features of the Crimean peninsula allow the creation of various routes - walking, bus, bike routes, speleo, horseback, and many others. Being a part of a tour (tourist product), a tourist route or "informative paths" geographically determine the movement of a tourist or a group of tourists in a certain direction during a trip. Today in the Crimea, there are hundreds of different tourist routes, which are distinguished by their length, attractiveness of the landscape, complexity of passage, etc. Within the travel, the tourist route can be divided by the direction on: linear, closed (ring), and radial. Formation of tourist routes, their choice depends on the purpose of tour, transport, the number of tourists and days of stay, the procedure for booking places in hotels. In one tour, any combinations of various options of tourist routes are possible.

As of 1975, there were over 350 All-Union and over 6 thousand planned local routes in the USSR. In the Crimea, there were 9 routes of all-Union importance:

No 21 - "Crimean automobile" (Simferopol and southern coast of the Crimea - Alushta, Karabakh, Yalta);

No 22- "Crimean mountain on foot" (Simferopol, Bakhchisarai, Sokolinoe, Ay-Petri, Yalta, Alushta);

No 23 - "Yalta (radial)" (Yalta, A.P. Chekhov's House museum, Nikitsky botanical garden, Gurzuf, Alupka, Uchan-Su falls, top of Ay-Petri, Grand Canyon);

No 24 - "Crimean mountain, walking";

No 91 - "Alushta (radial)";

No 110 - "On tops of the mountain Crimea, walking";

No 111 - "On guerrilla tracks of the mountain Crimea"; 
No 164- "Sevastopol (radial)";

No 323- "Crimean automobile" [10].

It should be noted that among the tourist routes of the Crimea, the most preferred are walking routes. Walking tourism is most effective, because it is a part of outdoor activities in which all types of recreation intersect, the process of restoration and development of human strength takes place on the basis of changes in activity. In addition, walking tourism is a cheaper form of travel using less comfortable means of accommodation, so it is affordable for people with average and even relatively low incomes [8]. Today, according to the register of "Tourist (excursion) routes" presented on the website of the Ministry of Culture and tourism of the Republic, about 70 routes from the 255 routes of Crimea belong to the category of informative walking types of tourism and are designated as cycling or walking routes [9]. For high-quality functioning of walking routes in the Crimea, it is necessary to carry out systematization and expert assessment of old routes, to carry out routine planning of the new ones. To achieve these goals, the following strategy for the development of "informative paths" has been developed.

The initial stage of development of the strategy for the organization of informative walking tourism is the definition of the mission and purpose of the tourism enterprises. Table 1 shows the developed strategy for the development of informative walking tourism.

Table 1. Strategy for the development of informative walking tourism.

\begin{tabular}{|c|c|c|}
\hline & $\begin{array}{l}\quad \text { Strategy of growth: } \\
\text { - variability of the nature of } \\
\text { surrounding circumstances for } \\
\text { informative walking tourism } \\
\text { to which management } \\
\text { decisions have to be opposed; } \\
\text { - granting equal opportunities } \\
\text { to all tourists; } \\
\text { - developed economy } \\
\text { environment providing profit } \\
\text { for the tourism industry. }\end{array}$ & \\
\hline \multirow[t]{2}{*}{$\begin{array}{l}\quad \text { Development strategies: } \\
\text { - flexibility in the system of the } \\
\text { organization of services of } \\
\text { informative walking tourism; } \\
\text { - carrying out organizational } \\
\text { policy; } \\
\text { - selection and arrangement of } \\
\text { personnel based on the analysis } \\
\text { of its qualification and the } \\
\text { prospects of advance (growth) } \\
\text { of informative walking tours. }\end{array}$} & $\begin{array}{l}\text { Strategy of development of } \\
\text { informative walking tourism }\end{array}$ & $\begin{array}{l}\text { Strategy of business: } \\
\text { - accounting of individual and } \\
\text { group forms of the organization } \\
\text { of tours; } \\
\text { - using objective methods for the } \\
\text { assessment of results of work of } \\
\text { personnel; } \\
\text { - encouragement of performance } \\
\text { of new and considerably } \\
\text { changed functions of the } \\
\text { program of formation and } \\
\text { maintenance of corporate } \\
\text { culture. }\end{array}$ \\
\hline & $\begin{array}{l}\text { Strategy of competitiveness: } \\
\text { - steady philosophy of process } \\
\text { of growth of competitiveness } \\
\text { of a product in the market of } \\
\text { tourist's services; } \\
\text { - assessment of the price } \\
\text { policy in the system of the } \\
\text { organization of services of } \\
\text { informative walking tourism; } \\
\text { - individual approach to tasks } \\
\text { of informative walking } \\
\text { tourism. }\end{array}$ & \\
\hline
\end{tabular}


The next stage is the development of private strategies for organizing the effective management of travel agency enterprises, the characteristics of which are given below (Figure 1).

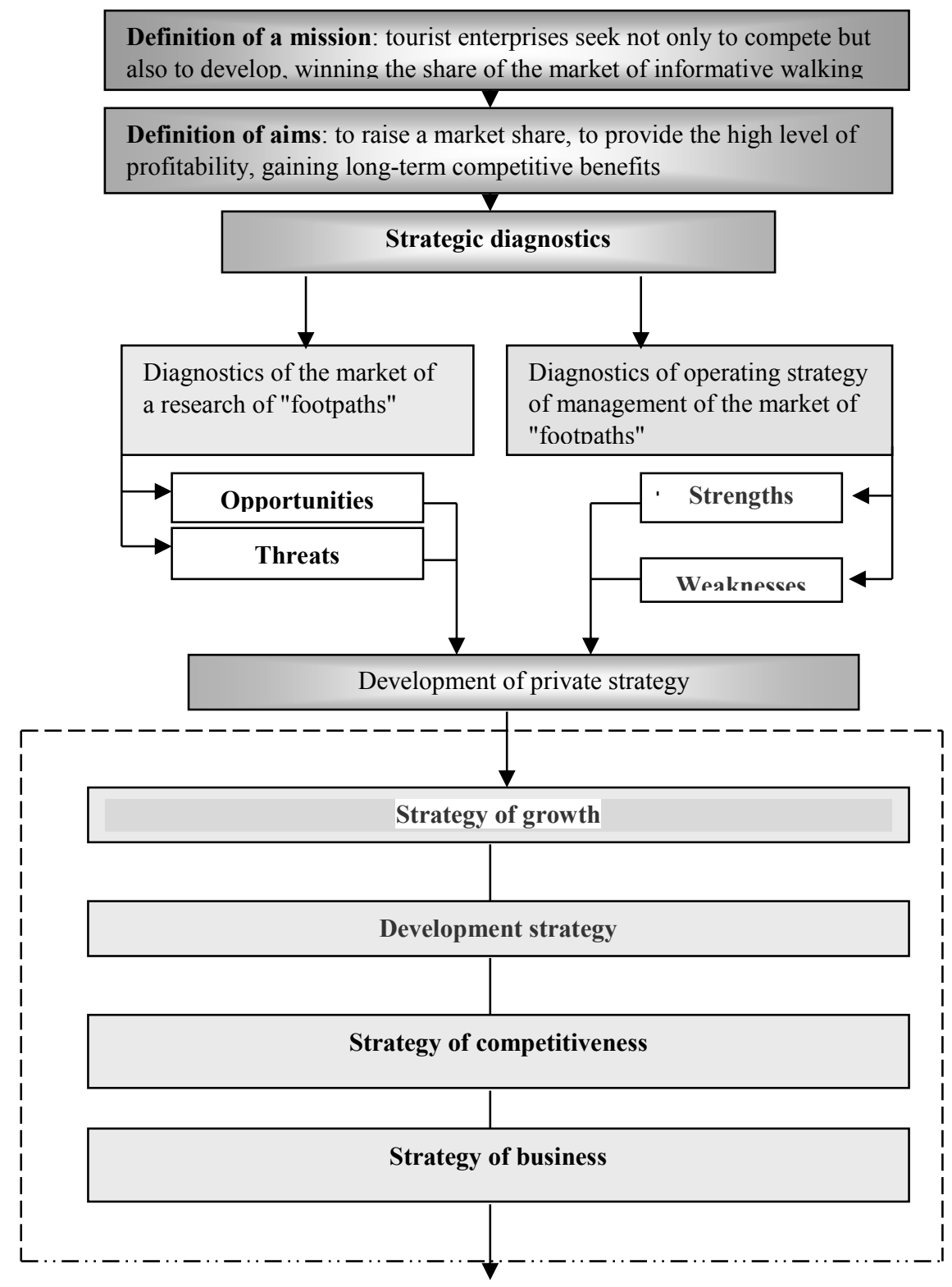

Development of tactical actions for realization of the strategy

Fig. 1. Recommended scheme for developing a strategy for the development of the "footpaths" market.

For performing strategic diagnostics of the market of informative walking tourism, it is necessary to analyze the external environment of functioning of the tourist enterprises. The market of informative walking tours, being also an element of the external environment, 
acts as its specific sphere in relation to features of orientation of the developed strategy of the organization of effective management of informative walking tourism. Definition of their opportunities and threats for the studied "footpaths" is the result of performing strategic diagnostics of the market of informative walking tours [11-13].

A necessary element in developing a strategy for organizing informative walking tours is the diagnosis of the current strategy for managing the market of informative walking tourism. This component of the proposed scheme serves as a starting point for identifying strengths and weaknesses for the study of "footpaths". The final stage of the offered scheme is development of tactical actions for implementation of the strategy for development of informative walking tourism. Presence of these components in the general scheme gives the chance to concretize provisions of the developed strategy and to make the strategic plan of its realization. Thus, the use of the proposed methodological approach to the development of a strategy for the development of " informative paths" to achieve compliance with the requirements of the tourism services market, existing goals, forms, methods, procedures, and projects. Depending on the size and market position, the development strategy can take two forms: concentrated and diversified. A diversified strategy for the development of effective market management of "footpaths" has been recommended to be used by large enterprises of tourism business that carry out different activities in the system of providing tourist services, and their structural divisions are located in different territories, in different micro-districts or settlements. The main objective of this strategy is to ensure the independent development of facilities based on mutual support and mutual assistance.

The market policy of "footpaths" is understood as the system of the principles, ideas, and the requirements defining the main directions of the project, its forms, methods and features of the organization. The main objective of the "footpaths" market policy is to timely ensure the optimal balance of the processes of acquisition and preservation of the natural environment, its development in accordance with the needs of the tourism industry, the requirements of current legislation, and the state of the tourist services market.

Based on the analysis of scientific research of scientists in the field of tourist routes, the main tasks of the policy of tourism industry enterprises include: timely providing paths with property of necessary quality (stands, indexes); providing conditions for realization of the rights and duties of the tourists provided by the legislation; rational use of resource capacity of the Crimea. The development strategy of "informative paths" and its most complete implementation largely depend on the choice of options for building the entire system for managing the market of informative walking tourism.

\section{Conclusion}

In the conditions of effective use of natural and resource capacity of the Crimea, strengthening of the competition and fight for the strong place in the market, the tourist enterprises should organize the activity in a new way. For the implementation of practice of organizing the routes of "informative paths", a highly efficient market tool was proposed to consolidate positions in the tourist market. Keeping the competitive advantages of the tours with the use of "informative paths", as well as the transition to a new level of development, is a set of actions for the integrated creation of conditions for the functioning of tourism enterprises in accordance with the changing market conditions and the developed strategy of its development.

\section{References}

1. M.B. Birzhakov, Introduction to tourism (Prod. house of Gerd, 2014) 
2. G.P. Dolzhenko, The history of tourism in pre-revolutionary Russia and the USSR (Publishing house of the Rostov university, 1988)

3. N.V. Zakaldayev, On foot across the Crimea or the Crimean paths (Attica, 2003)

4. I.V. Zorin, V.A. Kvartalnov, Touristic (Soviet Sport, 2001)

5. S.V. Ilkevich, The organizational and economic principles of design, development and arrangement of suburban foot paths (Service in Russia and abroad, 2017)

6. S.V. Ilkevich, E.S. Sakharchuk, Bulletin of Association of higher education institutions of tourism and service 2, 13-21 (2014)

7. A.B. Krutik, Science and technical register of the St. Petersburg state polytechnical university. Economic sciences 1(187), 32-41(2014)

8. S.A. Stepanov, E.S. Stepanova, Culture of people of the Black Sea Coast 45, 19-30 (2003)

9. V. Budnik, S. Chernyi, Procedia Engineering 150, 2150-2156 (2016)

10. S. Chernyi, N. Logunova, L. Aleksahina, 2017 International Conference "Quality Management, Transport and Information Security, Information Technologies" (IT\&QM\&IS) (2017)

11. A. Nyrkov, A. Zhilenkov, S. Sokolov, S. Chernyi, Automation and Remote Control 791, 195-202 (2018)

12. S. Chernyi, N. Logunova, L. Aleksahina, 2018 IEEE Conference of Russian Young Researchers in Electrical and Electronic Engineering (EIConRus) (2018)

13. S. Chernyi, N. Logunova, L. Aleksahina, 2018 IEEE International Conference "Quality Management, Transport and Information Security, Information Technologies" (IT\&QM\&IS) (2018) 